\title{
Apresentação do Dossiê “Paz nas Relações Internacionais”
}

Ramon Blanco ${ }^{1}$

Aureo de Toledo Gomes ${ }^{2}$

A presente edição da Conjuntura Global apresenta o Dossiê Temático intitulado "Paz nas Relações Internacionais". Esse Dossiê aglutina diferentes problematizações e reflexões acerca de um dos principais pilares da disciplina das Relações Internacionais, sendo este inclusive um dos seus propósitos ontológicos - a paz e a construção da paz no cenário internacional. Consequentemente, com esta edição, a Conjuntura Global acolhe e avança uma importante discussão dentro da disciplina. As discussões e problematizações aqui propostas não ocorrem em um vácuo acadêmico. Ao contrário, somam-se a outros diferentes esforços realizados de modo a avançar essa necessária e fundamental reflexão dentro da academia brasileira. Cabe mencionar os recentes esforços como, por exemplo, a fundação da Cátedra de Estudos para a Paz na Universidade Federal da Integração Latino-Americana, o I Encontro Brasileiro de Estudos para a Paz, realizado na Universidade de São Paulo, ou mesmo a criação da Rede de Pesquisa em Paz, Conflitos e Estudos Críticos de Segurança, contando com pesquisadoras e pesquisadores de todas as regiões brasileiras. Assim, com esta edição, a Conjuntura Global posiciona-se, também, na vanguarda desta discussão no país.

De modo a avançar com a sua contribuição nesta discussão, o presente Dossiê traz cinco artigos. Tais artigos, evidentemente, não têm por objetivo esgotar todos os assuntos e problematizações possíveis dentro da discussão em questão. Ao contrário, o Dossiê apresenta um mosaico com distintas problematizações críticas, apontando, assim, possíveis caminhos de serem avançados dentro de tal debate acadêmico. Este mosaico não poderia iniciar-se de modo mais relevante. 0 pontapé inicial vem mediante a importante

\footnotetext{
${ }^{1}$ Ramon Blanco é Professor no curso de Relações Internacionais e Integração da Universidade Federal da Integração Latino-Americana, onde coordena o Núcleo de Estudos para a Paz e a Cátedra de Estudos para a Paz, e é colaborador no Programa de Pós-Graduação em Ciência Política da Universidade Federal do Paraná.

${ }^{2}$ Aureo de Toledo Gomes é Professor no curso de Relações Internacionais e no Programa de PósGraduação em Relações Internacionais da Universidade Federal de Uberlândia.
} 
contribuição de Oliver Richmond. Em seu artigo intitulado "A Paz no Século XXI: Estados, Capital e Instituições Multilaterais versus Arbitragem Posicional, Mobilidade Diária, Redes e Multiverticalidade", Richmond traz uma discussão alargada acerca da paz, e da construção da mesma, no cenário internacional. Richmond problematiza, por exemplo, o fato de que, normalmente, as discussões sobre a construção da paz no cenário internacional tem subjacente às mesmas um debate acerca de uma arquitetura internacional, e se estas podem ser expandidas para uma governança global. Posteriormente, após discutir acerca das potencialidades de uma paz pós-liberal, Richmond traz um importante delineamento da arquitetura de paz contemporânea e das diferentes gradações de paz presentes na contemporaneidade, indo desde a paz liberal às distintas variações da paz híbrida.

A contribuição seguinte é desenvolvida por Gustavo Vieira e Rafael Batista. No artigo intitulado "Paz pelo Desarmamento Nuclear: Desafios Contemporâneos da Proibição com Base no Impacto Humanitário", os autores problematizam uma questão fulcral dentro dos Estudos para a Paz - o desarmamento nuclear. Mais especificamente, os autores avançam uma discussão bastante pertinente problematizando o papel que o Desarmamento Humanitário pode desempenhar dentro desta questão. Inicialmente, o artigo traz um panorama das diferentes fontes do Direito Internacional que versam sobre o desarmamento e o controle de armas no plano internacional. Sob este pano de fundo, o artigo reflete sobre as contribuições e limites de se problematizar a temática do desarmamento nuclear sob a ótica da recente abordagem humanitária, e não estratégicomilitar como frequentemente é feito. Nesse sentido, o artigo contribui significativamente para um importante e necessário alargamento na reflexão acerca das questões nucleares no cenário internacional.

Posteriormente, o Dossiê traz a reflexão de Juliana Bigatão, por meio do artigo intitulado "A Norma de Proteção de Civis nas Operações de Paz da ONU: Os Mandatos Robustos da Década de 2000". Neste artigo, a autora traz uma importante contribuição ao debate ao problematizar, por um lado, o modo pelo qual a proteção de civis foi incorporada à prática das operações de paz em cenários pós-conflito e, por outro, as possíveis implicações que a autorização de mandatos robustos, objetivando a proteção de civis no terreno, tiveram nos princípios básicos das operações de paz - a tríade de consentimento, 
imparcialidade e o não uso da força, salvo legítima defesa. Bigatão propõe o argumento de que a autorização deste tipo de mandatos não alterou a essência das operações de paz. De modo a desenvolver a sua reflexão, inicialmente o artigo traz um longo delineamento, operacionalizado por meio da análise de diferentes documentos centrais das Nações Unidas, sobre como a proteção de civis foi inserindo-se enquanto uma dimensão importante no modo como a própria ONU entende a prática das operações de paz pelo globo. Em seguida, Bigatão problematiza o modo como a questão da proteção de civis acaba por ser plasmada em diferentes resoluções e mandatos de distintas operações de paz onusianas pelo globo ao longo do período de 2001 e 2010.

Em seguida, o Dossiê traz uma indispensável crítica ao processo onusiano de construção da paz no cenário internacional, feita por Luis da Vinha em seu artigo intitulado "Creating Frankenstein States: The Persistent Quest for the Ideal Modern Polity". O autor pauta a sua reflexão acerca da construção da paz no cenário internacional por uma interessante analogia literária. Da Vinha estrutura sua análise crítica argumentando que o livro Frankenstein de Mary Shelley - ao invés do texto The Strange Case of Dr. Jekyll and Mr. Hyde de Robert Louis Stevenson como argumenta Oliver Richmond, por exemplo - fornece uma precisa analogia para um entendimento adequado acerca da agenda de (re)construção de Estados. De acordo com Da Vinha, esta analogia é precisa, sobretudo no que toca aos princípios que guiam tais processos. 0 autor discute, ao longo do seu texto, que o livro Frankenstein de Mary Shelley torna-se um importante símbolo da confiança e ilimitada ambição ocidental no pensamento científico, na racionalidade e na modernidade. Da Vinha argumenta que este mesmo espírito está presente nas organizações internacionais envolvidas nos processos de (re)construção de Estados em cenários pós-conflito. Para o autor, a mesma confiança na visão de progresso, no projeto Iluminista e na razão estrutura a intervenção de tais instituições na busca pela construção de entidades políticas ideais em cenários pós-conflito.

O presente Dossiê encerra a sua contribuição à discussão acerca da paz, e da construção da mesma, no cenário internacional trazendo a relevante reflexão de Roberta Holanda Maschietto. Em seu artigo intitulado "Consolidação internacional da paz versus percepções locais sobre a paz: encontros e desencontros", Maschietto traz à tona um importante debate dentro do debate em questão - a discussão da virada local nos 
processos de consolidação da paz. Mais precisamente, a autora centra a sua análise no conceito de paz híbrida e as limitações desta discussão no que toca à dimensão cultural da mesma. Reconhecendo as contribuições que esta discussão teve para trazer uma mudança no foco analítico da problematização acerca da consolidação da paz, incluindo também a visão dos atores locais acerca deste processo, Maschietto evidencia que mesmo com essa importante contribuição o debate ainda permanece pautado em torno do conceito de paz liberal. Isso, para a autora, é problemático. Em seu entendimento, isto limita a discussão realizada, em particular à dimensão cultural desta discussão, ao excluir da mesma diferentes elementos que não estejam relacionados à paz liberal.

Por fim, mas não menos importante, esta brevíssima apresentação não poderia finalizar-se sem um profundo agradecimento a Alexsandro Eugenio Pereira e a Caroline Cordeiro Viana e Silva, respectivamente Editor-Chefe e Editora Executiva da Conjuntura Global, em nome de todos/as os envolvidos/as no processo de construção e publicação desse Dossiê Temático, pelo pronto acolhimento do debate aqui realizado. Indubitavelmente, este é mais uma importante contribuição na disseminação e consolidação desta discussão dentro da academia brasileira. 